\title{
Estudio sobre jóvenes productores de cultura visual: evidencias de la brecha entre la escuela y la juventud
}

\section{Study on young people as visual culture producers: findings about the gap between the school and the youth}

\author{
IDOIA MARCELLAN-BARAZE \\ Universidad del País Vasco. \\ Departamento de didáctica de la expresión musical, plástica y corporal. \\ idoia.marcellan@ehu.es \\ Lander CAlvelhe \\ Universidad Pública de Navarra. \\ Departamento de Psicología y Pedagogía. \\ landercalvelhe@hotmail.com \\ IMANOL AgIRRE \\ Universidad Pública de Navarra. \\ Departamento de Psicología y Pedagogía. \\ imanol.agirre@unavarra.es \\ Amaia Arriaga \\ Universidad Pública de Navarra. \\ Departamento de Psicología y Pedagogía. \\ amaia.arriaga@unavarra.es
}

Recibido: 27 de noviembre de 2012

Aprobado: 5 de febrero de 2013

\begin{abstract}
Resumen
El presente artículo expone los primeros resultados obtenidos en el proyecto de investigación "Jóvenes productores de Cultura visual: competencias y saberes artísticos en la educación secundaria” (EDU 200913712), financiado Ministerio de Ciencia e Innovación del Gobierno de España. El principal objetivo de este proyecto es rastrear las maneras y situaciones en las que los jóvenes obtienen los saberes necesarios para producir imágenes y compararlas con los saberes que las instituciones educativas les proporcionan al respecto. El proyecto consta de varias fases y en este trabajo se presentan las evidencias obtenidas a partir de un cuestionario realizado durante el 2010-2011 a 786 jóvenes que cursaban $4^{\circ}$ de la ESO y $1^{\circ}$ de Bachillerato en varios centros del estado español. Los dos principales hallazgos que aquí se presentan son por un lado, una serie de evidencias que corroboran la existencia de la distancia entre los saberes que la escuela proporciona y los que los jóvenes obtienen fuera de ella para la producción de sus imágenes y, por el otro, la falta de consciencia mostrada por los jóvenes respecto al papel de los media como referentes que nutren sus producciones audiovisuales.
\end{abstract}

Palabras Clave: jóvenes, cultura visual, saberes escolares, entornos de aprendizaje, producción audiovisual. 
Marcellan-Baraze, I., Calvelhe, L., Agirre, I., Arriaga, A. (2013): Estudio sobre jóvenes productores de cultura visual: evidencias de la brecha entre la escuela y la juventud. Arte, Individuo y Sociedad, 25(3) 524-535

\begin{abstract}
This article presents the first analysed data from the research project "Youth as Visual Culture Producers: Artistic Skills and Savoir in Secondary Education" financed by the Spanish Innovation and Science Ministry (EDU2009-13712). The main aim of the project is to enquiry on the different ways and situations young people are learning to produce images and to compare the findings with what schools are offering them on the same field of knowledge. The project has various stages and this article draws out the evidences gathered by a questionnaire answered during 2010-2011 by 786 teenagers, ages 15 to 19 , from schools all around Spain. The two principal findings presented throughout the text are: on one hand, a group of evidences that corroborate the existence of a gap between the knowledge schools teach and that young people acquires outside school; and, on the other hand, the lack of consciousness young people present regarding the role of media as a source for their audiovisual production.
\end{abstract}

Key Words: youth, Visual Culture, School Knowledge, Learning enviroments, audiovisual production.

Marcellan-Baraze, I., Calvelhe, L., Agirre, I., Arriaga, A. (2013): Study on young people as visual culture producers: findings about the gap between the school and the youth. Arte, Individuo y Sociedad, 25(3) $524-535$

Sumario: 1. Orígenes de la investigación, 2. Recogida de datos: el cuestionario, 3.Primeros resultados, 3.1 Las actividades de producción visual, 3.1.1 Los medios para la realización de sus producciones, 3.1.2 Los usos y funciones de los diferentes medios en sus producciones, 3.2. Relación de los jóvenes con los medios , 3.2.1. Los referentes para la realización de sus producciones, 3.3. Relación de los jóvenes con los saberes escolares, 3.3.1. Los contextos iniciación en la producción de cultura visual, 3.3.2. El papel de la escuela en la formación para la producción de cultura visual, 4. Conclusiones, 4.1. La fotografía: ¿Uso generalizado y/u obligatoriedad de las formas de vida contemporánea?, 4.2. Los referentes y su nivel de consciencia: ¿Por qué sigue la imaginación dando respuesta a la creatividad?, 4.3. El reto educativo de la escuela y los saberes de los jóvenes: ¿Cuánto puede crecer la brecha? Referencias.

Este artículo recoge resultados del proyecto de investigación "Jóvenes productores de Cultura visual: competencias y saberes artísticos en la educación secundaria” (EDU 2009-13712), financiado Ministerio de Ciencia e Innovación del Gobierno de España.

\title{
1. Orígenes de la investigación
}

Mientras la escuela sigue buscando la rentabilidad y la competitividad, los cambios en la circulación de los saberes están configurando un "habitus" (Bourdieu, 1979), que sumerge a los jóvenes en procesos de habilidad comunicativa, innovación y creatividad (Nyboe, 2007), ahondando cada vez más la brecha entre los intereses institucionales y los de los sujetos aprendices. Como explica Martin Barbero (2003) mientras la escuela sigue centrada en la textualidad, nos encontramos ante un sujeto educativo que se expresa ordinariamente fuera de ella en idiomas no verbales, basados en su sensibilidad y en su corporeidad. Un sujeto, cuya complicidad expresiva con los códigos de la tecnología audiovisual, trasciende su rol de receptor y lo convierte en productor autónomo de una 
gran diversidad de imágenes, tanto en formatos y soportes como en temáticas, en un entorno lleno de estímulos y referentes audiovisuales (en adelante englobaremos todas estas prácticas y producciones bajo la denominación de cultura visual).

La preocupación por un posible desajuste entre lo que ofrece la escuela y lo que realizan los jóvenes nos llevó a emprender esta investigación para indagar sobre los saberes que ponen en práctica en su faceta de creadores de cultura visual y así compararlos con los que la escuela les ofrece. Esta es precisamente la novedad que presenta este trabajo, en comparación con otras investigaciones comprometidas con el estudio de capacidad de influencia de la cultura visual, especialmente la de tipo mediático, entre los jóvenes.

Muchos de estos estudios (Giroux, 1994; Kincheloe, 2002; Macedo y Steinberg, 2007; Marcellán, 2009; Steinberg y Kincheloe, 1997) se han propuesto analizar críticamente el poder de las imágenes mediáticas en la infancia y la juventud desde diversos fundamentos y objetivos. Algunos han enfatizando el análisis semiótico e ideológico (Aparici y Matilla, 1987; Masterman, 1985;Pérez-Tornero, 1994); otros el poder de las imágenes como constructoras sociales (Masterman, 1985; Buckingham, 2000), mientras que una tercera vía ha puesto el énfasis en la influencia de los medios como constructoras de identidades (Morduchowicz, 2003). Por lo general estos estudios han buscado promover políticas educativas de tipo proteccionista, de alfabetización o de concienciación para un consumo crítico de las imágenes producidas y difundidas desde los regímenes de visualidad de la cultura contemporánea. A nuestro juicio, estas posiciones relegan a un segundo plano la tarea de reconocimiento y empoderamiento de la capacidad de la juventud y su intervención directa en la creación de una cultura visual lo más emancipada posible.

No obstante, bien es cierto que hace ya tiempo que opiniones muy influyentes como las de Buckingham (2003), Martínez de Toda (1999), Masterman (1985) o Ramos (2001) señalan que es preciso progresar de este análisis crítico sobre los medios a una formación que habilite al estudiante para usarlos en su propia producción. Recientemente Ferrés y Piscitelli (2012) incidían en la necesidad de potenciar la cultura participativa junto al desarrollo de la capacidad crítica, en la línea de Pablo Ramos, experto en Educación para la Comunicación o "Educomunicación”, quien explica a este respecto:

\footnotetext{
"Se concibe a la comunicación como un proceso de puesta en común y, por tanto, de valoración y reconocimiento de sus actores como personalidades que se construyen en su relación con el otro y consigo mismo. A su vez, un nuevo concepto de ciudadanía se ha ido gestando desde la sociedad civil, lo que implica abrir nuevos espacios para el ejercicio de la participación, la expresión y la comunicación como derechos inalienables de sectores considerados como "objetos" y no "sujetos" de derechos, tal es el caso de la niñez. Desde esta nueva perspectiva, ha de promoverse una educación para la comunicación que supere el hiato entre una formación para la recepción o "lectura" de los medios (práctica mayoritaria) $y$ otra para la producción creativa o "escritura" de mensajes y que redimensione el papel del sujeto, de receptor a emisor de mensajes y de espectador a protagonista de procesos comunicacionales, gestados desde sus propias necesidades y capacidades." (2001: sin paginar).
}

Por tanto, la presente investigación pretende ahondar en la faceta productiva de la juventud porque a nuestro juicio la preocupación no reside en que ésta sea exclusivamente 
usuaria, como pudiera deducirse de la literatura científica generalizada, sino en que son las formas culturales proporcionadas, principalmente, por las industrias mediáticas, las que están alimentando el lado creativo de jóvenes y adolescentes. De tal modo, es la lógica mercantil la que, en ausencia de las instituciones educativas, termina dando cierta formación, modelos y visibilidad a las creaciones de los jóvenes. Programas televisivos como Fama a Bailar y Operación Triunfo en España, o MTV Teen Age Clicks a nivel internacional, son las muestras de cómo las industrias del ocio y el entretenimiento se han adelantado a la educación formal en el interés por el potencial de las formas culturales que los jóvenes están desarrollando al margen del mundo de los saberes escolares. De hecho si observamos las actividades culturales más usuales en los entornos juveniles, inmediatamente percibimos que la tecnología, por un lado, y las industrias de la cultura y el ocio, por el otro, otorgan cada vez más protagonismo a la faceta creadora de quienes eran recientemente considerados meros usuarios.

\section{Recogida de datos: el cuestionario}

En este contexto, hemos finalizado la primera fase de nuestra investigación en la que a través de un cuestionario hemos querido realizar una aproximación general a las producciones visuales de los jóvenes (qué tipo de imágenes producen, qué temas abordan, los motivos, los referentes en los que se inspiran, etc.) y al tipo de saberes que ponen en práctica en estas producciones.

Para la elaboración del cuestionario se partió de modelos ya probados tales como: Encompass (Education and National Culture: a comparative study of pupil attitudes to secondary schooling) que permite detectar las relaciones entre "las culturas nacionales, las biografias individuales y las prácticas de aula, en la creación de contextos de aprendizaje (...) y en las diferentes maneras de vincularse a los alumnos a las escuela y a los aprendizajes" (Osborn et al., 2003:13), el utilizado en el proyecto de la Universidad de Barcelona "Repensar el éxito y el fracaso escolar de la educación secundaria desde la relación de los jóvenes con el saber"(EDU 2008-03287) y un cuestionario utilizado en el proyecto de la Universidad Pública de Navarra "Estudio de los imaginarios visuales y musicales de los estudiantes de secundaria en Navarra: aplicaciones educativas" (Aguirre, 2009 y 2006). Así mismo se contó con la colaboración de varios jóvenes que accedieron a realizar una prueba piloto con el fin de analizar, junto con los miembros del equipo, la pertinencia de las diferentes preguntas, la idoneidad de los temas planteados y las dificultades de léxico que pudieran dificultar su comprensión por los futuros destinatarios. De esta manera comenzamos a trabajar desde un inicio teniendo en cuenta uno de los principales objetivos de la investigación: introducir a los jóvenes como agentes activos dentro del proyecto. La adopción de este objetivo, que deviene de un particular posicionamiento ante la actividad académica, dio lugar a poner en marcha un proceso de reflexividad (Macbeth, 2001) que acabó siendo fructífero, ya que los aprendizajes derivados han trascendido las decisiones sobre el propio tema de la investigación y han dado lugar a la generación de tantas certezas como nuevas dudas en torno a la misma. El resultado de dicha colaboración fue la emergencia de nuevos conocimientos experienciales sobre el objeto de la investigación, que nos llevó a reexaminar nuestras preguntas iniciales, el marco teórico, e incluso el método de análisis (Paulus, Woodside $\&$ Ziegler, 2008). 
Así, una vez realizados los ajustes necesarios, el cuestionario se distribuyó de forma equitativa y representativa en el territorio MEC y entre las comunidades autónomas que tienen currículo propio para la educación secundaria. En total participaron 786 jóvenes de $4^{\circ}$ de la ESO y $1^{\circ}$ de bachillerato de diferentes centros educativos del estado español. En la mayoría de los casos miembros del equipo acudieron a los centros y allí explicaron los pormenores de la investigación a los jóvenes encuestados pudiendo resolver así las dudas de los participantes, mientras que en otras ocasiones se contó con la colaboración de profesorado de secundaria, que anteriormente también había colaborado con nuestro grupo de investigación.

En ningún caso buscábamos seguir un criterio de representatividad estadística, ni de tener como implícita la existencia de diferencias por comunidades autónomas o centros de secundaria. Lo que pretendíamos era reunir un número suficiente y variado de respuestas que nos permitiera obtener indicios de cómo los jóvenes se sitúan frente a las relaciones con el saber en la escuela secundaria. En concreto sobre cómo interactúan son los saberes artísticos y estéticos que obtienen tanto dentro de las clases como fuera de ellas y las repercusiones en sus producciones.

El cuestionario final lo constituyeron 24 preguntas de tipo test y divido en 3 secciones:

1. La primera sección destinada a rastrear las actividades, en general, que los jóvenes realizan en relación con la producción de cultura visual.

2. Una segunda específica destinada a profundizar en las circunstancias en las que discurre la actividad relacionada con aquella modalidad productiva que cada uno de los encuestados practique con mayor frecuencia o intensidad.

3. Y por último una sección destinada a indagar sobre la relación entre los saberes escolares y los que ponen en juego en su actividad preferente como productores de cultura visual.

Los datos obtenidos se han transcrito a una base de datos on-line (encuesta fácil. es) y a una base de datos File-Maker permitiéndonos cruzar los datos y realizar los consiguientes análisis. Los primeros datos obtenidos a partir de este material constituyen el cuerpo de este trabajo entre los cuales destacamos los siguientes indicios (Sebeok y Umiker-Sebeok, 1987).

\section{Primeros resultados}

\subsection{Las actividades de producción visual}

\subsubsection{Los medios para la realización de sus producciones}

Si tuviéramos que hacer un resumen de lo que nos ha aportado esta fase de la investigación uno de los aspectos más reseñables del mismo es que los jóvenes encuestados nos han ofrecido una imagen de su actividad como productores de cultura visual diferente en algunos aspectos a la que habíamos previsto cuando iniciamos la investigación. No nos ha extrañado que una abrumadora mayoría realicen fotografía, pero sí que nos ha sorprendido que actividades tradicionalmente asociadas a la juventud 
(graffiti, cómic, o páginas web) hayan resultado ser tan minoritarias como las que tradicionalmente se consideran ajenas a ellos, como las pinturas en lienzo, por ejemplo. Así el 58\% de los 786 encuestados dijeron practicar 'siempre' o 'con frecuencia' la fotografía. Este dato por sí mismo no significaría gran cosa si no fuera porque contrasta con el $42 \%$ de quienes eligieron el dibujo en cuadernos y el $4 \%$ y el $3 \%$ de quienes dijeron realizar graffiti y cómic respectivamente, junto con un 5\% para el diseño de páginas web. Estas últimas por debajo, incluso, de la pintura en lienzos (7\%), la animación (9\%), el video (11\%) o la realización de carteles y portadas $(12 \%)$.

\subsubsection{Los usos y funciones de los diferentes medios en sus producciones}

Preguntados por los fines u objetivos con los que realizan sus imágenes, en sus respuestas vemos que el uso y función de sus producciones cambia según sea el vehículo empleado. No obstante, en términos generales, se observa una tendencia a distinguir entre actividades de producción más orientadas hacia la documentación frente a otras que se consideran más apropiadas para la creación. Así, el 77\% de los encuestados consideran que realizan fotografías con la finalidad principal de "compartir sus vivencias". Los videos en el $52 \%$ de los casos y el valor más alto a continuación de éstos es el del dibujo que sólo es considerado una manera de compartir vivencias en el 9\% de los casos. Cuando nos referimos a la función de "documentar lo que pasa a su alrededor" ocurre algo similar: el $65 \%$ afirma usar la fotografía con este objetivo y el $45 \%$ hace lo análogo con el vídeo, mientras que de nuevo el dibujo presenta el valor siguiente más alto, si bien no pasa del 11\%. Cuando se trata de "producir historias", el vídeo gana a la fotografía ( $48 \%$ frente a $26 \%$ ) pero en este caso la invitación a dar más espacio a la creatividad o la inventiva que ofrece la idea de "producir historias" parece dejar más espacio a la emergencia de otras formas de producción visual como el cómic (30\%) o de nuevo el dibujo $(26 \%)$.

\subsection{Relación de los jóvenes con los medios}

\subsubsection{Los referentes para la realización de sus producciones}

En cuanto a los referentes de su producción, a pesar de que se pudiera pensar que proceden de lo que proporcionan los medios, los datos que nos aportan hablan exactamente de lo contrario. Es abrumadora la mayoría de respuestas que dicen que el origen de sus imágenes, 'siempre' o 'con frecuencia', está en su propia imaginación (76\%). Este dato también contrasta y contradice la creencia general de que los jóvenes toman sus referentes imaginarios de Internet, ya que este último, sólo provee de imágenes (siempre o con frecuencia) al 32\%, mientras que la televisión, los videojuegos o la publicidad lo harían, según sus respuestas, en el 12, 13 y $11 \%$ de los casos respectivamente. Especialmente significativo es que el $46 \%$ de los encuestados afirmen que nunca toman imágenes de los videojuegos para sus producciones o que el 37\% digan que nunca las toman de la publicidad. 


\subsection{Relación de los jóvenes con los saberes escolares}

\subsubsection{Los contextos iniciación en la producción de cultura visual}

Respecto a los marcos en los que los jóvenes inician la producción de diversas imágenes las 786 encuestas nos han mostrado que son claramente marcos informales de aprendizaje en los que prima una visión autodidacta. Así, casi la mitad de los encuestados (44\%) afirman que nadie les enseñó, que empezaron por su cuenta, observando trabajos de otras personas, mientras que un $37 \%$ considera que su primer aprendizaje se produjo de la mano de amigos o conocidos. Un 17\% señaló al ambiente familiar y tan sólo un 13\% reconoció como lugar de iniciación el entorno escolar. Ni siquiera los marcos extraescolares han sido reconocidos como lugares de aprendizaje puesto que sólo un 9\% de las personas que contestaron el cuestionario reconocieron que la afición e iniciación a la actividad de producción de imágenes que practicaba se gestó en esos entornos no formales de la educación extraescolar.

\subsubsection{El papel de la escuela en la formación para la producción de cultura visual}

En cuanto al papel que juega la escuela en el desarrollo de sus producciones las respuestas de los jóvenes confirman un vacío: por un lado la institución escolar y el profesorado son vistos como agentes que no se interesan nada (50\%) o casi nada $(21 \%)$ por la actividad productora de los jóvenes, frente a sólo un $5 \%$ que creen que se interesan mucho o un $9 \%$ que consideran que se interesan bastante. Por otro lado, la opinión generalizada es que la escuela no contribuye nada o casi nada a mejorar su producción visual: el $72 \%$ de la muestra jamás realiza su actividad junto a profesores, mientras sólo un $6 \%$ lo hace siempre o con frecuencia. De la misma manera, si se trata de ofrecer temas para las creaciones propias, el 59\% de los encuestados considera que la escuela no aporta nada o casi nada (sólo un $12 \%$ cree que aporta mucho o bastante). En todo caso la escuela les ofrece 'mucho o bastante' ayuda para el aprendizaje de técnicas, así lo ha señalado un $27 \%$ de los encuestados. O es vista como un lugar que propicia interacciones, si no con el profesorado, sí con otros compañeros. Muestra de ello es que el $30 \%$ de los encuestados considera que favorece mucho o bastante la posibilidad de intercambiar ideas con sus colegas, frente a un importante $46 \%$ que cree que no lo favorece nada o casi nada. De hecho cuando tienen un problema o duda sólo el $22 \%$ dice buscar la opinión experta, más de la mitad recurre a Internet, casi un $40 \%$ recurre a amigos y la cuarta parte simplemente cambia de idea sobre su producción.

\section{Conclusiones}

El proyecto de investigación continúa y todavía quedan muchos datos por explorar y líneas en las que profundizar, pero con los resultados expuestos hasta ahora podemos avivar la discusión con las siguientes cuestiones: 


\subsection{La fotografia: ¿Uso generalizado y/u obligatoriedad de las formas de vida contemporánea?}

El hecho de que el medio más usado para sus producciones sea la fotografía es compresible ya que es el más accesible hoy día para los jóvenes. Este dato corrobora la hipótesis de una brecha creciente entre los saberes que se trabajan en la escuela y los intereses de la juventud, ya que la fotografía hoy por hoy, tiene un lugar muy anecdótico dentro de la educación secundaria obligatoria española. Mientras tanto, fuera del ámbito escolar, es muy habitual que a través de herramientas de base visual como "My Space", "Fotolog", y sobre todo de "Tuenti" - la red social usada por el 69\% de los españoles de entre 11 y 20 años según el ONTSI (Ureña, 2011)- los jóvenes no sólo compartan sus producciones sino que las reelaboren y las personalicen ejercitando así su faceta productiva. Ahora bien, como indican Leander \& Frank (2006), la industria informática del ocio no solo ofrece a los jóvenes la opción de ser coautores, partícipes y protagonistas de su propio mundo, sino que en algunos casos incluso les obliga a dicha personalización. La cultura del "customized", del "tunning" y el hágalo usted mismo se impone como parte del nuevo sensorium que habitan los jóvenes. En el caso de las culturas juveniles esto se hace especialmente patente en los juegos en los que cada jugador, antes de iniciar la partida, debe conformar sus personajes o equipos, determinar cuáles son sus utillajes, su aspecto físico, sus comportamientos e, incluso, el entorno en el que actúan.

Así es que, a nuestro parecer, sería interesante un cambio de tendencia en los ámbitos educativos, que se tuvieran en cuenta estas realidades y se concibiera a los jóvenes como productores de imágenes, no sólo como consumidores.

\subsection{Los referentes y su nivel de consciencia: ¿Por qué sigue la imaginación dando respuesta a la creatividad?}

Los jóvenes encuestados han mostrado cierta indolencia o inconsciencia respecto a los referentes que nutren sus producciones. Esta cuestión ya había sido detectada en otra investigación anterior (Marcellán y Aguirre, 2008). En aquella ocasión eran niños y niñas de entre 9 y 10 años y sus padres y madres los que mostraron cierta ignorancia ante el poder formativo de los medios y sus imágenes, tanto a nivel temático como formal. Si tenemos que aventurar alguna hipótesis de trabajo para analizar el hecho de que los jóvenes de este estudio mayoritariamente aludan como fuente de inspiración a su propia imaginación, nos inclinamos a pensar que es debido al carácter mayoritario de sus producciones (aparentemente fotografías de sus actividades cotidianas) o bien a que, por algún motivo, no son conscientes de qué resortes imaginarios están operando en la selección de motivos o recursos visuales que ponen en juego en sus producciones. Los jóvenes encuestados comparten por tanto una sensación de autodidactismo y de concebir la producción de imágenes como una actividad de carácter casi estrictamente personal en la que apenas hay conciencia de su dimensión social o cultural. En cualquier caso como indican Leander \& Frank (2006) a partir de la investigación que realizaron sobre los casos de una joven creadora de páginas web y de un joven diseñador de personajes para jugar on-line, en realidad, ni los sujetos somos tan libres como pretenden los diseñadores, ni finalmente hacemos todo lo que los medios tienen prescrito para nosotros. 


\subsection{El reto educativo de la escuela y los saberes de los jóvenes: ¿Cuánto puede crecer la brecha?}

Como concluíamos anteriormente, mediante las respuestas recogidas en el cuestionario hemos podido evidenciar nuestra hipótesis de que la escuela no ofrece los saberes que los jóvenes necesitan para la producción de artefactos propios de la cultura visual. Tanto los lugares y situaciones de la iniciación como los procesos de aprendizaje se materializan en el entorno de las amistades, dando lugar a formas más o menos difusas o poco conscientes de aprendizaje colaborativo, basado en la imitación y el contagio, mientras que los saberes expertos y la propia escuela quedan prácticamente al margen de su actividad, presentando valores muy bajos en el conjunto de las posibles estrategias que adoptarían en el caso de encontrarse con dificultades.

A nuestro juicio, la gran mayoría de estas prácticas y aprendizajes que los jóvenes ponen en juego cuando producen imágenes en el ámbito informal, alejadas de un proyecto educativo crítico y responsable, están abocados en demasiadas ocasiones a repetir los estereotipos sociales o a reproducir las conductas y criterios ideológicos más reaccionarios de nuestras sociedades. De hecho, muchos estudios apuntan a que los jóvenes reproducen estereotipos de género y de raza e imitan las formulas más problemáticas de los medios comerciales en sus propios gráficos, videos o páginas web creadas a través o durante las sesiones de educación mediática (Fleetwood, 2005; Tyner, 1998; Sefton-Green y Sinker, 2000; Soep, 2005a). En nuestro caso, esta cuestión del grado de influencia de esos referentes en sus propias producciones está por confirmarse en una siguiente fase de la investigación en la que analizaremos varias de las imágenes que producen los jóvenes investigados. El estudio de estos fenómenos es importante, según Leander \& Frank (2006), porque además nos permite comprender cómo las entidades comerciales, creadores de juegos, etc. fabrican deseo e identidad y cómo los jóvenes asumen la tarea prescrita de manera creativa, reelaborando estas propuestas en beneficio de la construcción de su subjetividad. Por eso, una vez más, nos encontramos ante un fenómeno que merece ser reconsiderado desde la educación, porque nos reta a pensar sobre cómo los ensamblajes sociales, técnicos y culturales adoptan la forma de productos para la creación de identidades y, al mismo tiempo, cómo los sujetos los reproducimos, intervenimos y/o contestamos.

Por tanto, desde el ámbito educativo formal convendría revisar si las competencias y saberes que se proporcionan a los jóvenes y adolescentes son el equipamiento que éstos necesitan no sólo para producir cultura visual sino para comprenderla. Y preocuparse por cómo articular estos saberes escolares con los que los jóvenes manejan en su vida ordinaria. De hecho, los programas y productos audiovisuales orientados al entretenimiento tienen tanta participación o más en la construcción de valores, creencias y actitudes de las personas, bien sean jóvenes o adultas, que los generalmente considerados educativos. Toda esta cultura visual nos está instruyendo en aquellas cuestiones más propias de lo emotivo, lo moral y lo afectivo, dimensiones de lo humano que a menudo quedan fuera de la visión logocentrista de los entornos escolares. Así es que mientras los sistemas educativos formales no cambien, esta parcela de la formación seguirá siendo cubierta, en gran medida, por los diversos artefactos mediáticos, televisivos, cinematográficos, etc. y lo que es más preocupante, sin la consciencia de ello. 


\section{Referencias}

AGUIRRE. I. (2009). Culturas juveniles y ambientes escolares. En JIMÉNEZ L; AGUIRRE, I \& PIMENTEL, L.G. Educación artística, cultura y ciudadanía. Madrid: Fundación Santillana-OEI; 45-58.

AGUIRRE. I. (2006). Los imaginarios visuales y musicales de los jóvenes. Datos para una cartografía de la experiencia estética juvenil y la educación. En "Interdisciplinary Dialogues in Arts Education" Internacional Insea Congress. Viseu (Portugal).

APARICI, R. y MATILLA, A. (1987). Imagen, video y educación. Fondo de Cultura Económica, Madrid: Paideia.

BOURDIEU, P. (1991). La distinción: criterios y bases sociales del gusto. Madrid: Taurus.

BUCKINGHAM, D. (2002). Crecer en la era de los medios electrónicos. Madrid: Morata.

BUCKINGHAM, D. (2003). Media education: literacy, learning and contemporary culture. Cambridge: Polity Press.

FLEETWOOD, N. (2005). Authenticating practices: Producing realness, performing youth. En MAIRA, S. y SOEP, E. (eds.) Youthscapes: The popular, the national, the global, Philadelphia: University of Pennsylvania Press; 155-172.

FERRÉS, J. y PISCITELLI, A. (2012). La competencia mediática: propuesta articulada de dimensiones e indicadores. Comunicar,38, XIX; 75-82. (http://dx.doi.org/10.3916/ C38-2012-02-08)

GIROUX, H. (1994). Disturbing Pleasures: Learning Popular Culture. New York: Routledge. (http://dx.doi.org/10.2307/358882).

KINCHELOE, J. (2002). The Sing of the Burger: McDonald's and the Culture of Power. Philadelphia: Temple University Press.

LEANDER, K. y FRANK, A. (2006) The Aesthetic Production and Distribution of Image/Subjects among Online Youth. E-Learning, 2 (3); 185-206. (http://dx.doi. org/10.2304/elea.2006.3.2.185)

MACBETH, D. (2001). On "Reflexivity". En Qualitative Research: Two Readings, and a Third. Qualitative Inquiry, 1(7): 35-68. (http://dx.doi. org/10.1177/107780040100700103)

MACEDO, D. y STEINBERG, S. R. (eds.) (2007). Media Literacy. New York: Peter Lang.

MARCELLÁN, I. y AGUIRRE, I. (2008). El valor educativo de los medios. Comunicar, 31, XVI; 529-535. (http://dx.doi.org/10.3916/c31-2008-03-046).

MARCELLÁN, I. (2009). Sobre como la educación artística podría potenciar la capacidad crítica ante los medios. En AGRA PARDIÑAS, M.J. et alter (coord.) Desafios da educação artística em contextos ibero americanos, Portugal: Edições. APECV;98-11.

MARTIN BARBERO, J (2003). Saberes hoy: diseminaciones, competencias y transversalidades. Revista Iberoamericana de Educación, 32; 17-34.

MARTÍNEZ DE TODA, J. (1998). Las seis dimensiones en la educación para los medios. En Comunicación. Estudios venezolanos de comunicación, 103; 33-47.

MASTERMAN, L. (1993). La enseñanza de los medios de comunicación. Madrid: Ediciones de la Torre Madrid. 
MORDUCHOWICZ, R. (coord.) (2003). Comunicación, medios y educación. Barcelona: Octaedro.

NYBOE, L., (2007). Authority, pedagogy and competence in young people's media production practices. Closing Conference of the Competence and Media Convergence (CMC) Research Programme, University of Oslo.

OSBORN, M. ; MCNESS, E.; BROADFOOT, P.; RAVN, B.; PLANEL, C. y TRIGGS, P. (2003). A World of Difference? Comparing Learners across Europe. Maindenhead: Open University Press.

PAULUS, T; WOODSIDE, M. y ZIEGLER, M. (2008). Extending the conversation: qualitative research as dialogic collaborative process. The Qualitative Report 13(2); 226-243.

PÉREZ TORNERO, J. M. (1994). El desafio educativo de la televisión. Barcelona: Paidós.

RAMOS, P. (2001). Tres décadas de Educomunicación en América Latina: los caminos del plan DENI. Quito: OCLACC.

SEBEOK, T. y UMIKER-SEBEOK, J. (1987). Sherlock Holmes y Charles S. Pierce. El método de la investigación. Barcelona: Editorial Paidós.

SEFTON-GREEN, J. y SINKER, R. (2000). Evaluating creativity: Making and learning by young people. London: Routledge.

SOEP, E. (2005) Making hard-core masculinity: Teenage boys playing house. In MAIRA S. \& SOEP, E. (Eds.), Youthscapes: The popular, the national, the global.. Philadelphia: University of Pennsylvania Press; 173-191.

STEINBERG, S. R. y KINCHELOE, J. (ed.) (1997). Cultura infantil y multinacionales. Madrid: Morata.

TYNER, K. (1998). Literacy in a digital world: Teaching and learning in the age of information. Mahwah, NJ: Lawrence Earlbaum Associates.

UREÑA, A. (coord.) (2011). Las redes sociales en Internet. ONTSI - Observatorio Nacional de las Telecomunicaciones y de las SI. Fondo Europeo de Desarrollo Regional. (http://www.ontsi.red.es/media/2011 $\square$ 12/1322729705471.pdf - Última consulta $01 / 12 / 2011)$. 
